\title{
Retraction Note: Development of an abnormal ocean circulation and Japanese visualization teaching system based on the Internet of Things
}

\section{Wenjing Chen ${ }^{1}$}

Published online: 23 November 2021

(c) Saudi Society for Geosciences 2021

Retraction Note: Arabian Journal of Geosciences (2021) 14: 1455

https://doi.org/10.1007/s12517-021-07763-3

The Editor-in-Chief and the Publisher have retracted this article because the content of this article is nonsensical. The peer review process was not carried out in accordance with the Publisher's peer review policy. The author agrees with this retraction.

The original article can be found online at https://doi.org/10.1007/ s12517-021-07763-3

Wenjing Chen

chenwenjing688@163.com

1 School of Foreign Languages, Luoyang Normal University, Luoyang 471934, Henan, China 